\title{
stats - stosta
}

\section{$\mathfrak{I n \mathfrak { j } a l t .}$}

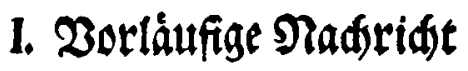

5. I

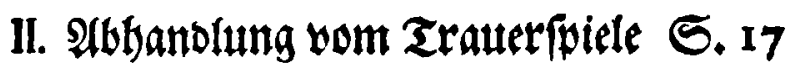

III. Cramers poetifofe Leberfeţung Det

$$
\mathfrak{P} \text { aramen }
$$

5. 69

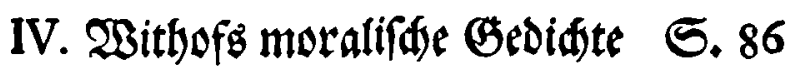
V. Briefe bon Dem jetegigen 3 uffand Der

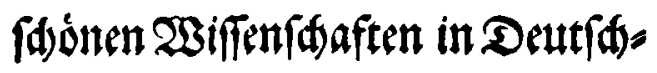
Iand

5. 107

VI. Lowth Praelectiones de poefi facra
Hebraeorum
S. 122

VII. Prophezenungent auf $\mathfrak{d a g}$ Iaher 1756 .

5. 134

VIII. The London Marchant $\quad$ S. 161

IX. $\mathfrak{D} \mathfrak{n}[\mathfrak{d}$ dren Gedidte $\quad$ S. 168

$$
x_{3} \quad \text { X. Frant }
$$




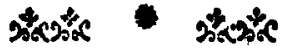

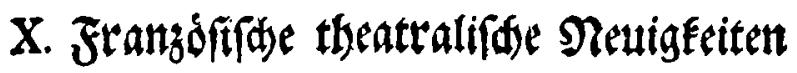

$$
\text { 5. } 180
$$

1) Raderidten von Dem franzóffffent Zleater in $\mathfrak{P a r i s} \quad$ S. 182

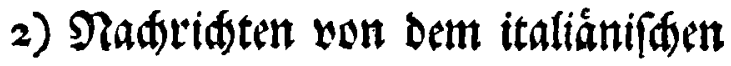
Theater in Parie $\quad$ S. 194

3) PIan Des \{uftipiels l'Epoufe fuivante

5. 202

4) Plan der Fêtes Parifiennes 5.204

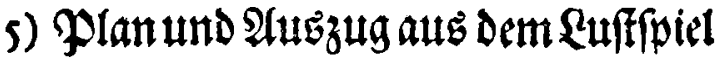
la Coquette corrigée $\quad$ S.204

XI. Betmifdete $\mathfrak{N a d f r i d f t e n t} \quad$ S. 222

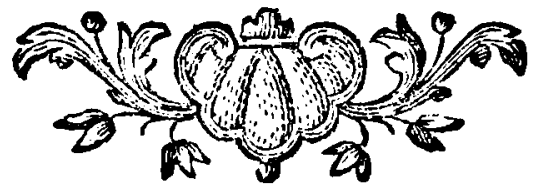

